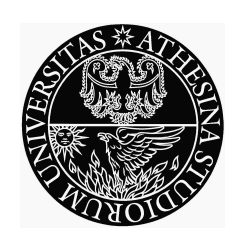

UNIVERSITA' DEGLI STUDI DI TRENTO

DIPARTIMENTO DI ECONOMIA

\title{
THE UNDERGROUND ECONOMY AND THE UNDERDEVELOPMENT TRAP
}

\author{
Maria Rosaria Carillo \\ and \\ Maurizio Pugno
}

Discussion Paper No. 1, 2002 
The Discussion Paper series provides a means for circulating preliminary research results by staff of or visitors to the Department. Its purpose is to stimulate discussion prior to the publication of papers.

Requests for copies of Discussion Papers and address changes should be sent to:

Prof. Andrea Leonardi

Dipartimento di Economia

Università degli Studi

Via Inama 5

38100 TRENTO ITALY 


\title{
THE UNDERGROUND ECONOMY AND THE UNDERDEVELOPMENT TRAP*
}

\author{
by
}

\author{
Maria Rosaria Carillo* and Maurizio Pugno*
}

\begin{abstract}
A general equilibrium model is proposed which assumes that firms hire both official and unregistered workers as imperfect substitutes, that entrepreneurs differ in their ability to increase the efficiency of official labour, and that this ability is due to heterogeneous original ability and to Marshallian (non-linear) externalities. In equilibrium, smaller firms hire fewer official workers and are less efficient. If externalities increase sufficiently when firms are numerous, two stable equilibria exist where the number and the size of firms, the proportion of official employment, overall output and efficiency are, respectively, small (the trap) and large. The increase of individual ability due to, e.g., educational policies, has positive effects on the equilibrium number of firms, overall output, and labour regularisation. High and evenly distributed entrepreneurship also make it more likely that increased externalities and penalties on the underground economy will have positive effects. These results may contribute to the current debate on the underground economy in the Southern areas of Italy
\end{abstract}

JEL Code: $\mathrm{J} 21, \mathrm{O} 17$

* Acknowledgement: We wish to thank the participants at the Conference "Differenziali regionali e politiche del lavoro" (Salerno, 2-3/11/00) and, in particular, Luigi Bonatti for comments on a previous draft of the paper. The research has been financed by Murst.

* Università degli Studi di Napoli "Parthenope".

- Dipartimento di Economia, Università di Trento

via Inama 5, I-38100 Trento, Italia tel. +39+0461+882232-01-03; fax +39+0461+882222

e-mail: mpugno@ risc1.gelso.unitn.it 


\section{Introduction}

The "underground economy" is an awkward subject for both economists and policy makers. Economists find it difficult to define and to measure, while their main explanations of it are highly partial. Indeed, they produce extremely diverse estimates of the underground economy in the same country, depending on the definitions and the method used (Lippert and Walker 1997). ${ }^{1}$ By contrast, explanations of the phenomenon at the theoretical and empirical levels are usually restricted to the heavy weight of the tax burden and to excessive regulations (Schneider 1997; Feige 1989; Tanzi 1980). Policy makers are discomfited by the fact that the underground economy is detrimental to tax revenues and, more generally, to social order, whereas it is able to generate employment and income.

A step towards better understanding and management of the problem of the underground economy is to consider it in connection with the structure of the economy, whether this is advanced or less developed. Estimates agree that the underground economy is most widespread in the less developed countries, and, within the Oecd, in Greece, Italy, Spain and Portugal (Schneider and Enste 2000, European Commission 1998; Schneider 1997). Nevertheless, the tax burden is not only particularly heavy in Greece and in Italy, it is also heavy in the Scandinavian countries, and even in Austria (Oecd 1997), which displays a very low incidence of underground economic activity. ${ }^{2}$ But the most striking evidence concerns the South of Italy compared to the rest of the country. In

${ }^{1}$ Tanzi (1999), in surveying the literature, observes that these estimates, in percentages of GDP, "range from $1.4 \%$ to $47.1 \%$ for Canada, and from $6.2 \%$ to 19.4 for the US [...] In Germany [they range] from 14.5 to 31.4 ".

${ }^{2}$ Johnson, Kaufman, and Zoido-Lobaton (1998) do find that more regulations are associated with a larger share of underground economy, but after controlling for Gdp per capita. 
fact, the Southern Italian regions are characterised both by a less developed economic structure and by a more widespread underground economy, although they are subject to the same tax system and regulations - if not lighter ones - as the Northern regions. These facts can be explained if we look at the different forms assumed by underground activity. In the Mediterranean countries or regions, the non-registration of labour is standard practice for both firms, though to different extents, and private employees, who otherwise are faced by unemployment with no social benefits available. The economic structure thus mainly consists of small firms, which can compensate for technological inefficiencies by low unregistered labour costs (Donolo and Capparucci 1999; Commissione Lavoro della Camera dei Deputati 1998). By contrast, in the Northern countries or regions of Europe and in the US unregistered work is typically of secondary importance, and it is often pursued by those who are already employed. ${ }^{3}$ Therefore, one may state the stylised fact that a widespread underground economy is associated with inefficient techniques, few and small units and low output; and conversely that a small proportion of underground activity in the economy is linked with more efficient techniques, more and larger units, and a greater output.

It might be thought that development, and hence the reduction of the underground economy, is an automatic process. However, this does not seem always to be the case. Analysis of convergence among per capita GDPs in the European regions clearly shows that many poor regions tend to stagnate, or even that they form a low income club of regions (Tondl 1999; Paci 1997). Even more clearly, recent trends in many regions of Southern Italy, together

\footnotetext{
${ }^{3}$ Another component of unregistered labour consists of immigrants, but its relative importance may be great in the richest countries and regions as well as in the other areas (European Commission 1998; Petersen 1998). 
with the persistent, if not increasing, diffusion of underground practices, suggest the existence of an underdevelopment trap.

This paper is a first attempt to study the interaction between the underground economy and the economic structure as characterised by the size and the number of firms, as well as by overall productivity and output. It seeks to describe the case of an economy trapped in an equilibrium comprising a high proportion of underground activity, small sized and few firms, and overall low productivity and output. Conversely, it is possible to represent an economy in a better equilibrium where these characteristics are reversed.

The theoretical literature on the underground economy in a general equilibrium setting is not substantial, and it concentrates mainly on the effects of fiscal policy, paying little or no attention to the heterogeneous performance of firms, or to other characterisations of the economic structure (Bental et al. 1985; Ginsburgh 1985; Bennett 1990; Agenor and Aizenman 1999; De Geijsel 1985). When the connection between sluggish development and a large underground economy is studied, the erosion of the tax base in order to finance growth-enhancing public services has been considered (Loayza 1996; Johnson, Kaufmann, and Zoido-Lobaton 1998). However, South Italy has not been subject to revenue constraint because it is subsidised by North Italy. In this case, instead called into question has been the excessive labour cost fixed in the more productive part of the country (Brunetta and Ceci 1998). This paper, however, concentrates on the role of entrepreneurship, rather than on the provision of public services or on rigid wages.

The problem of determining an interior solution for the size of the underground economy is usually solved by distinguishing between two goods, 
officially and unofficially produced, and thus two kinds of demand for them. ${ }^{4}$ Instead, in Rauch (1991) the economic structure is characterised by the allocation of heterogeneous entrepreneurship between the sectors, one informal and the other formal, and by the smaller-sized and less productive firms of the former. This approach is able to provide an interior solution, although both output and labour are homogeneous, but it fails to avoid the assumption of specialised firms in the two sectors, which is often unrealistic. ${ }^{5}$

The model presented here follows the latter approach, but it is also able to deal with mixed firms, i.e. those which employ both unregistered and official labour. It assumes that the potential entrepreneur - depending on his/her ability to train official labour better, and on the given possibility of evading the fiscal burden on labour - chooses the best mix, thus also choosing the technique for producing the same good. The second key feature of the model, intended to capture an important aspect of industrialisation, is the assumption of Marshallian externalities among firms. This assumption, combined with the given distribution of entrepreneurial ability, makes two general stable equilibria possible: one "good", and one 'bad". This result suggests that development and underground activity may be induced into a trap.

The policy implications to be drawn from the model are interesting, not only as regards the possibility of passing from the "bad" to the "good" equilibrium, but also to check the popular wisdom that policies intended to reduce the underground economy also reduce the number of firms and overall

${ }^{4}$ Alternatively, De Gijsel (1985) adopts a Nash solution, as due to different preferences of both the employers and workers between official and unregistered work. Bonatti (2000) fixes the numbers of firms in the legal sector and in the informal sector.

${ }^{5}$ The allocation of entrepreneurial talent approach was introduced by Lucas (1978) and then developed by Murphy, Shleifer, and Vishny (1991). For a first application of it to study of the underground economy see Pugno (2000). 
output. This is of particular interest as regards the North/South dualism in Italy, and even more so as regards the different areas of South Italy.

The paper is organised as follows: section 1 sets out the assumptions of the model, sections 2 and 3 develop the solution of the model, section 4 carries out some exercises in comparative statics, and draws policy considerations, section 5 concludes, while three appendices give the mathematical proofs.

\section{The Assumptions of the Model}

Let us assume that numerous firms competitively produce one good by using homogeneous labour in two different ways, either by registering it and paying the relative taxes and contributions, or by not registering it and thus avoiding this fiscal burden.

The different treatment of labour by firms is taken a step further here, i.e. in the techniques of production. In the case of official labour, in fact, rules and norms, usually established by private contracts or collective bargaining, are applied, but they are not applied in the case of unregistered labour. When workers are officially employed, the relationship between them and firms is more stable and more closely integrated, and this makes it possible, or easier, to foster workforce learning activities - either unintentional, such as 'learning by doing', or intentional, such as 'training on the job'. In fact, learning activity can be likened to specific investments that can take only place in the presence of stable relationships. By contrast, unregistered labour does not usually imply a stable and systematic relationship between workers and firms, so that a learning process rarely occurs, or does not happen at all. The learning activity carried on by legal workers implies that they can use more efficiently the technology adopted by firm, thus exhibiting a higher productivity. Illegal workers, instead, 
do not reach the same level of productivity since they do not acquire, or do not acquire in the same degree, the knowledge related to the level of technology adopted by firm. The hypotheses that the learning activity is directly related to the level of technology and that it is more probable when there are stable relationships between workers and firms have been advanced by several authors (Acemoglu 1997, Burdett and Smith 1996 and Stevens 1994) ${ }^{6}$. In this paper we extend these hypotheses to the case of legal and illegal workers, since one of major difference between these two kinds of workers is not only the different cost sustained by firms for them, but also the different types of working-relationship: stable and integrated in the case of legal workers, marginal and unstable in the case of illegal workers. These differences may have a direct effect on the learning by doing carried on by workers and, as a consequence, on their productivity. In order to capture these facts, two different techniques of production are assumed, depending on whether official or unregistered labour is employed.

Formally, the microeconomic production function specifies two different efficiencies for labour, as follows:

$$
y_{i}=\left\lfloor B_{i} l_{l, i}^{\alpha}+\beta l_{s, i}^{\alpha}\right\rfloor \quad \text { with } 0<\alpha<1 \text { and } \beta \geq 0
$$

where $y$ indicates output of the only good in this economy whose price is the numeraire, $l_{l}$ and $l_{S}$ are respectively the official and the unregistered labour employed. The subscript $i$ refers to the $i$-th firm. $B_{i}$ is the productivity of legal workers, which is different from the productivity of illegal workers $(\beta)^{7}$, and it represents firm's best technology, insofar as $B_{i}>\beta$ (although this restriction is not necessary to the model).

\footnotetext{
${ }^{6}$ See for an application to a growth framework Aghion and Howitt (1998, ch. 6).

${ }^{7}$ Hence, $l_{l}$ and $l_{s}$ are not perfect substitutes, while neither of them is essential.
} 
At this regard, a further crucial assumption of the model is that the firm's best technology depends on the entrepreneurial ability and on the positive externalities arising from existing firms. Individual entrepreneurial ability originates from the exogenous natural propensities of individuals which can be thought of with a fixed distribution over population (cf. Baumol 1990). While the externalities are assumed to be of Marshallian type, and are intended to capture the typical effects of the industrial district. In fact, a crucial feature in the development of an industrial district is that firms should be sufficiently numerous within a given area to be able to display productive interrelatedness. ${ }^{8}$ Hence, externalities may not be linear in the number of firms; rather, they may accelerate when the industrial district becomes established.

Formally, let us assume that $B_{i}$ depends on entrepreneurial ability and on economy wide externalities according to the following equation:

$$
B_{i}=B\left(E_{i}, E\right)=A\left(E_{i}\right) T(E)
$$

where $A\left(E_{i}\right)$ is the original individual ability, assumed to differ among individuals, so that they can be ranked in descending order of ability according to the following distribution function:

$$
A_{i}=\eta E_{i}^{\eta-1} \quad \text { with } 0<\eta<1 \quad E_{i} \in \mathrm{R}
$$

$E_{i}$ indicates the $i$-th entrepreneur, who ranges from 0 to $E, E$ is a measure of active firms. Since entrepreneurs are ranked, and run one firm each, $E$ is also the group of the ablest entrepreneurs. ${ }^{9}$ Hence, $B_{i}$ is decreasing in $E_{i}$ for any given $E$.

\footnotetext{
${ }^{8}$ In Becattini's (1979:47) words: 'The Marshallian industrial district consists of [...] a localised thickening of interindustrial relationships" [our translation].

${ }^{9}$ This distribution is chosen because it belongs to the well-known Paretian type, but care must be taken over the limiting case of $E \rightarrow 0$. The conclusions of the paper are qualitatively the same if the distribution is of Gaussian type.
} 
The function $T$, which captures the externality effects, is increasing in $E$, so that the larger is $E$, the higher is the ability of all the active entrepreneurs, which represents the best technology. In particular, $T$ is assumed to be of the logistic type, as follows:

$$
T(E)=\frac{1}{1+e^{v-z E}}
$$

It is therefore possible to specify the productivity of the legal workers in the marginal firm, which is the least productive firm of the group $E$, and hence it is the $E$-th firm:

$$
B=B(E)=A(E) T(E)=\frac{\eta E^{\eta-1}}{1+e^{\nu-z E}} .
$$

This function has two decreasing traits at the extreme, where decreasing individual ability prevails, and it can have an increasing trait in the middle, where externality can prevail (see Fig.1). In fact, in the first trait the number of firms is too small for sufficient externalities to arise; in the second trait the number of firms may reach the critical mass required to form an industrial district, and hence to raise the efficiency of all firms, thereby overcoming the decreasing effect of individual ability; in the third trait externalities approach exhaustion, and the shape of ability distribution prevails. Note that for any given $E$, and hence for any point $(E, B)$, there exists a function $B_{i}$, which is decreasing in $E_{i}(<E)$ until $E_{i}=E$, where $B_{i}=B$.

Finally we define the cost function which includes official labour, as weighted by the fiscal burden, and the unregistered labour, which is also burdened to some extent, because of the risk of being fined. A third cost component is assumed: namely a fixed cost, which captures the effort to enter the market. Thus:

$$
c_{i}=w_{l}(1+t) l_{l, i}+w_{s}(1+m) l_{s, i}+\bar{c}
$$




$$
\text { with } 0<t<1 \quad 0<m<1 \text { and } m<t
$$

where $c_{i}$ is the total cost for the firm, $w_{l}$ and $w_{s}$ are the wage rates of official and unregistered labour respectively, $t$ is the tax rate, inclusive of social contributions, and $m$ is the fiscal burden on unregistered labour, which is due to a multiple of evaded taxes times the probability to be fined. Fixed cost is denoted by $\bar{c}$.

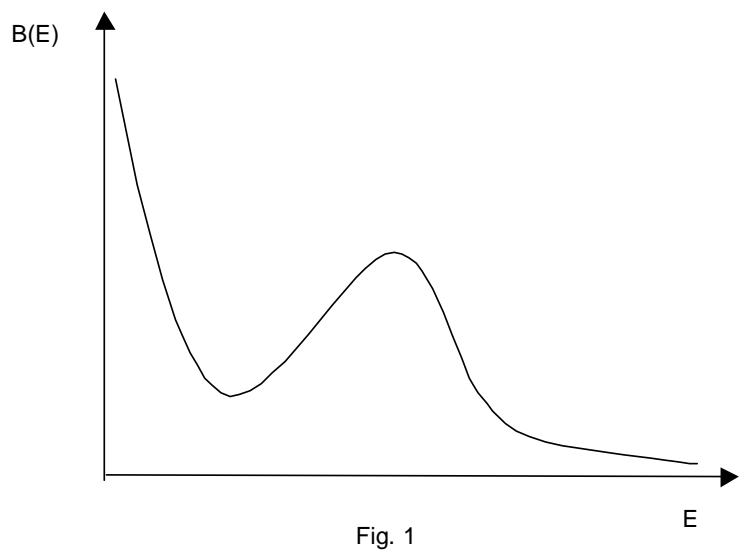

As concerns the labour market, let us assume that it is populated by a fixed number of individuals: $L=\bar{L}$. They have an identical utility function linear in consumption and derive no disutility from supplying labour. Each individual is endowed with a one-unit flow of labour, which is offered inelastically. Therefore $L$ is also equal to the aggregate flow of labour supply. Finally, the labour market is assumed to be perfectly competitive.

\section{Microeconomic Equilibrium}

Firms choose their amounts of official and of unregistered labour by maximising total profits given by:

$$
\pi_{i}=y_{i}-c_{i}
$$


where $\pi_{i}$ is the total profits, inclusive of the quasi-rent earned by the entrepreneurs as far as they can exhibit ability. The two labour demands for official and unregistered labour respectively, derived from first order conditions, are:

$$
\begin{aligned}
& l_{l, i} *=\left\{\frac{\alpha \eta E_{i}^{\eta-1}}{w_{l}(1+t)\left(1+e^{\nu-z E}\right)}\right\}^{\frac{1}{1-\alpha}} \\
& l_{S, i} *\left\{\frac{\alpha \beta}{w_{S}(1+m)}\right\}^{\frac{1}{1-\alpha}}
\end{aligned}
$$

Hence, the ratio between $l_{l} *$ and $l_{s} *$ of the $i$-the firm is equal to:

$$
g_{i}=\left\{\frac{w_{S}(1+m) \eta E_{i}^{\eta-1}}{\beta w_{l}(1+t)\left(1+e^{v-z E}\right)}\right\}^{\frac{1}{1-\alpha}} .
$$

Eqs. (6) and (8) indicate that the greater the ability of the $i$-th entrepreneur, the larger the size of his firm, and the greater the firm's degree of regularisation. A first analytical result is thus obtained: the link among size, efficiency and the proportion of registered labour as characteristics of heterogeneous maximising firms.

By substituting equations (6), (7) into eqs. (1) and (4), and then into the profit function (5), we obtain the following equation:

$$
\pi_{i}^{*}=(1-\alpha)\left[A\left(E_{i}\right) T(E) l_{l}^{\alpha} *+\beta l_{S}^{\alpha} *\right]-\bar{c}=(1-\alpha) y *\left(E_{i}, E\right)-\bar{c} .
$$

The $i$-th entrepreneur will enter the market if he will find positive (equilibrium) profits, i.e. if $\pi\left(E_{i}, E\right)^{*} \geq 0$. Since heterogeneous entrepreneurs imply heterogeneous profits, entrepreneurs will enter the market until the least 
able one finds zero profit, i.e. $\pi\left(E_{i}=E\right)^{*}=0$. In this case, everyone will have made the best choice, and hence the equilibrium number of active firms has been determined.

As regards workers, these may choose to work as official or unregistered labour according to which arrangement ensures higher indirect utility. Further, we assume that workers are interested only in wages net of fiscal burden. Thus, given the assumptions on the utility function, the workers' decision rule about the type of job to take, legal or illegal, becomes:

$$
w_{l} \geq w_{S} .
$$

\section{General Equilibrium}

This economy will be in equilibrium if three conditions hold: no further firm enters or leaves the market; no further worker changes type of employment; the labour market is in equilibrium. Given the assumption of free entry, the first equilibrium condition implies that for the marginal entrepreneur, who is least able, $\pi^{*}=0$, while the second condition implies that the wages of official and unregistered workers in equilibrium will be equal. Finally the third condition is the usual market clearing condition whereby aggregate labour supply is equal to the aggregate labour demand.

By substituting the optimal values for $l_{l}$ and $l_{S}$ (equations (6) and (7) respectively) into equation (1), and then into (9), and by taking into account that in equilibrium $w_{S}=w_{l}=w$, the zero-profit condition for the marginal firm becomes: 


$$
w_{P}=\left(\frac{1-\alpha}{\bar{c}}\right)^{\frac{1-\alpha}{\alpha}}\left[(B(E))^{\frac{1}{1-\alpha}}\left(\frac{\alpha}{1+t}\right)^{\frac{\alpha}{1-\alpha}}+\beta\left(\frac{\beta \alpha}{1+m}\right)^{\frac{\alpha}{1-\alpha}}\right]^{\frac{1-\alpha}{\alpha}}
$$

Equation (11) is drawn in Fig. 2:

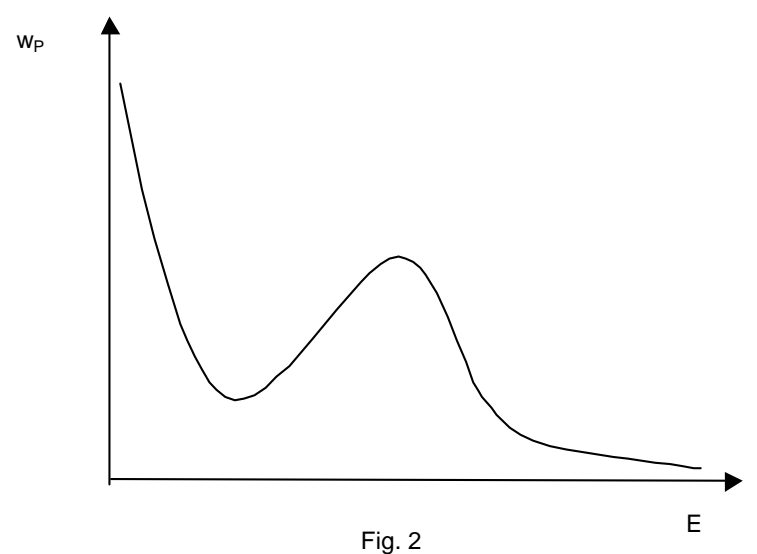

This curve, which resembles the $B(E)$ curve, shows different combinations of wage and number of active firms, the marginal of which exhibits zero profit. Hence, it does not reflect the technological conditions of the infra-marginal firms. These firms benefit both from the externalities given by the number of active firms like all the others, and from the individual higher ability of the entrepreneur, thus earning positive profits. ${ }^{10}$ All firms take externalities as given, while the curve in Fig. 2 depicts the conditions where externalities are endogenous. Note that if firms, for a given wage, conjecture the enjoyment of a

${ }^{10}$ For a given $E$ the curve identifies the wage level that reduces the profit of the $E$-th firm to zero, while the other active firms $\left(E_{i}\right)$, which are on the left of the $E$-th along the $x$-axis, would require a higher wage level to reduce profits to zero. Hence, a decreasing zero-profit curve for all active firms may be drawn for each $E$, which implies a certain degree of externality. 
certain degree of externality which is generally different from the endogenous one, they adjust in the right direction. ${ }^{11}$

The labour market equilibrium condition is:

$$
\bar{L}=L_{l}+L_{S}
$$

where $\bar{L}$ is the aggregate labour supply equal to the population, and it will normalised to 1 , while $L_{l}=\int_{0}^{E} l_{l, i} d i$ and $L_{S}=\int_{0}^{E} l_{S, i} d i$ are the aggregate demands for official and unregistered labour respectively.

Substituting eqs. (6) and (7) into the integrals above, and then into eq. (12), the labour market equilibrium condition becomes:

$$
w_{L}=\left(\left(\frac{\alpha}{1+t}\right)^{\frac{1}{1-\alpha}}\left(\frac{\eta E^{\eta-\alpha}}{1+e^{\nu-z E}}\right)^{\frac{1}{1-\alpha}} \frac{1-\alpha}{\eta-\alpha}+E\left(\frac{\beta \alpha}{1+m}\right)^{\frac{1}{1-\alpha}}\right)^{1-\alpha}
$$

Equation (13) shows different combinations of the wage and the number of firms ensuring equilibrium in the labour market. Obviously, the relationship between wage and number of firms is positive, since eq. (13) reflects the labour supply constraint. In equilibrium it must be that $w_{P}=w_{L}$.

Therefore the system formed by equations (11) and (13) gives rise to equation (14).

$$
\left(\frac{1-\alpha}{\bar{c}}\right)^{\frac{1}{\alpha}}\left[\left(\frac{\eta E^{\eta-1}}{1+e^{\nu-z E}}\right)^{\frac{1}{1-\alpha}}\left(\frac{\alpha}{1+t}\right)^{\frac{\alpha}{1-\alpha}}+\beta\left(\frac{\beta \alpha}{1+m}\right)^{\frac{\alpha}{1-\alpha}}\right]^{\frac{1}{\alpha}}=\left(\frac{\alpha}{1+t}\right)^{\frac{1}{1-\alpha}}\left(\frac{\eta E^{\eta-\alpha}}{1+e^{v-z E}}\right)^{\frac{1}{1-\alpha}} \frac{1-\alpha}{\eta-\alpha}+E\left(\frac{\beta \alpha}{1+m}\right)^{\frac{1}{1-\alpha}}
$$

${ }^{11}$ If, for example, a certain degree of externality is conjectured, and hence a zero-profit curve for all firms can be drawn, a given wage would fix the conjectured number of active entrepreneurs on this curve. If the least able of them realises positive (negative) profits, more entrepreneurs enter (leave) the market, until the marginal firm is on the curve depicted in Fig.2. 
From this equation the following can be stated.

Proposition 1: There exists at least one equilibrium that yields the wage ( $\left.w^{*}\right)$ for which the labour market clears and no firm enters or leaves the market, thus determining $E^{*}$. Moreover, there may also be multiple equilibria, one of which is unstable and two are stable. The first stable-equilibrium is characterised by a wage and a number of firms less than those of the second stable-equilibrium.

Proof: see Appendix 1.

Fig. 3 depicts the above results by approximating equation (13) as a straight line.

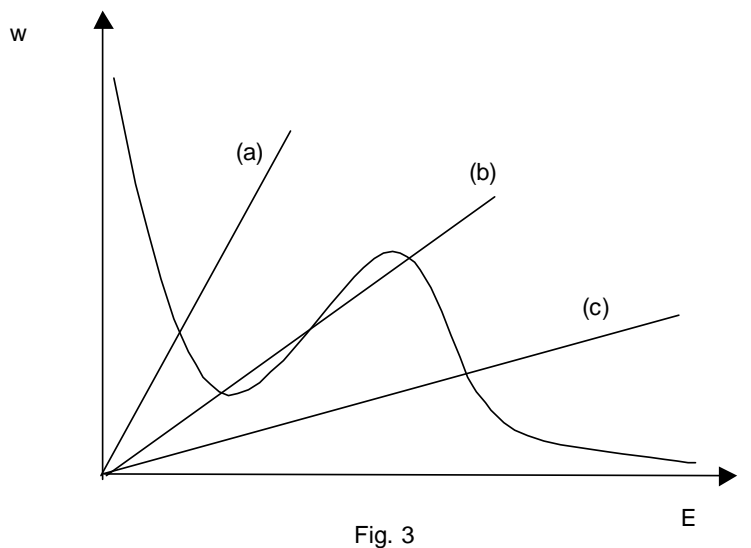

The model thus yields at least one equilibrium, where a positive but not exhaustive proportion of underground economy is determined, and where all firms are involved in this mixed activity to different extents depending on their size. 
In cases (a) and (c) there is a unique equilibrium. However the two cases are quite different. In case (a) the intersection between the two curves takes place in the first trait of the zero-profit curve, when the number of firms is so low that it does not give rise to substantial effects of Marshallian externalities. The size of firms is relatively small, and the underground proportion is relatively large. This equilibrium can represent an economy in the first stages of its development. Case (c) shows a completely different situation, although wages may be similar. In fact, the externalities have been largely exploited, and the zero-profit curve is decreasing because of the natural scarcity of individual ability. This may be the case of a more mature economy where firms are able to exploit their potential for growth. Case (b) is an intermediate situation. It shows the possibility that multiple equilibria may arise. In this case economies that start from different numbers of firms may reach a completely different equilibrium, even if they have equal parameters values. One equilibrium is characterised by a larger amount of firms and is similar to case (c), another has fewer firms and is similar to case (a).

The different cases can be also compared in terms of the aggregate output generated. In this regard we can state:

Proposition 2: $i$ ) The condition $\frac{1+m}{1+t}>\alpha$, is sufficient in order that a greater equilibrium number of firms generates a larger amount of aggregate output ; ii) in the case of multiple equilibria, for any values of parameters, equilibrium with a larger number of firms is Pareto-superior and is characterised by both average and marginal firm with a degree of regularisation $(g)$ higher than that exhibited by both average and marginal firm in the low equilibrium. 
Proof: see appendix 2.

Proposition 2 enables us to compare the different kinds of equilibrium discussed above according to the level of aggregate output generated. It states that if the ratio between the price of unregistered labour and the price of official labour, which because of the assumptions made is lower than 1 , is larger than the parameter which captures the productivity of labour factor (irrespectively of whether it is legal or illegal), the equilibrium with a lower number of firms gives rise to a lower amount of aggregate output. As regards the case of multiple equilibria, for any values of parameters the lower equilibrium generates a level of aggregate output lower then that associated with a high equilibrium; moreover, in the low equilibrium firms use unregistered labour more intensively. The case of Pareto-ranked multiple equilibria is particularly interesting, since it implies the possibility that the economy, at an initial stage of its development, may be induced into an underdevelopment trap.

\section{Comparative Statics and Policy Considerations}

Simple exercises of comparative statics can help us to identify policies to reduce unregistered labour, increase the efficiency of the economy, and, possibly, to enable escape from the underdevelopment trap. Interesting parameters of the model for policies are: $m$, which is the fiscal burden on the unregistered labour; $z$, which is a measure of externalities; and $\eta$, which 
captures the entrepreneurial ability that does not depend on the economic environment. ${ }^{12}$

The fiscal burden may be increased by tighter fiscal controls and by raising penalties. Externalities may be increased by providing or incentivising public services for legal activities. Individual entrepreneurial ability may be increased by educational policies.

All these policy measures increase the degree of regularisation of the firms ( $g$-ratio), and then reduce the overall size of the underground economy, as seen in the previous section. However, popular wisdom holds that reduction of the underground economy also reduces the overall number of firms and the level of overall economic activity. It is thus interesting to check whether the model confirms this result.

Let us first observe that the restriction $\alpha<\frac{1+m}{1+t}$ is not strict and can be taken for granted. In fact, even in an extreme case where $m=0$ and $t=0.5$, it becomes $\alpha<0.67$, and the data on the labour share in income not generally give a higher figure. Hence, a larger number of firms always produces a higher amount of output. This is a reasonable result when studying the underground economy, which is usually populated by small firms that cannot significantly exploit scale returns.

The effectiveness of policies can be studied by considering the following propositions.

${ }^{12}$ The uncomfortable properties of the Paretian distribution around the asymptote suggest us to ignore that part in which $E$ is very small. In fact, a rise in $\eta$ increases individual ability if $\frac{\partial\left(\eta E^{\eta-1}\right)}{\partial \eta}=\frac{1+\eta \ln E}{E^{1-\eta}}>0$. 
Proposition 3: A higher level of parameter $\eta$ implies a greater equilibrium number of firms $\left(E^{*}\right)$, and a higher level of overall output $\left(Y^{*}\right)$, in the case of one equilibrium. In the case of two stable equilibria these expansionary effects remain valid, in particular the lower equilibrium may disappear.

Proof: see Appendix 3.

This proposition suggests that policies intended to increase individual entrepreneurial ability are always effective in both reducing the underground economy and expanding the number of firms and overall output. Moreover, this kind of policy may push the economy on to the right track, if it is caught in the underdevelopment trap.

Proposition 4: A higher level of parameter $z$ implies greater equilibrium numbers of firms, and higher levels of overall output $\left(Y^{*}\right)$ in both cases of one and two stable equilibria, if $\frac{1+m}{1+t}<\frac{\eta-\alpha}{\alpha(1-\alpha)}$. While a higher level of parameter $z$ has ambiguous effects on the equilibrium numbers of firms, and on the levels of overall output $\left(Y^{*}\right)$ in both cases of one and two stable equilibria if $\frac{1+m}{1+t}>\frac{\eta-\alpha}{\alpha(1-\alpha)}$. However, if the equilibrium number of firms tends to 0 , the expansionary effects are anyhow safe.

Proof: see Appendix 3.

This proposition suggests that policies intended to increase positive externalities of production through the employment of official labour are generally effective in both reducing the underground economy and expanding overall output. Whereas an increase in $\eta$ makes entrepreneurial ability more 
evenly distributed, and thus favours small firms, an increase in $z$ favours the middle-able entrepreneurs. Hence, in this case the demand for labour is considerably increased, and this may raise wages and push small firms out of the market. This particular case occurs when small firms are very widespread because of very small $\eta$.

Proposition 5: A higher level of parameter $m$ implies greater equilibrium numbers of firms, and higher levels of overall output $\left(Y^{*}\right)$ in both cases of one and two stable equilibria, if $\frac{1+m}{1+t}<\frac{\eta-\alpha}{1-\alpha}$. A higher level of parameter $m$ implies smaller equilibrium numbers of firms, and lower levels of overall output $\left(Y^{*}\right)$ in both cases of one and two stable equilibria if $\frac{1+m}{1+t}>\frac{\eta-\alpha}{1-\alpha}$.

Proof: see Appendix 3.

This proposition suggests that policies intended to increase controls and penalties, though effective in reducing the underground economy, has ambiguous effects on the number of firms and on overall output. If controls and penalties are initially small in amount relatively to entrepreneurial ability, their increase is beneficial to overall output, but if they are initially of large amount, their increase is detrimental. In the case of two (stable) equilibria, increasing controls and penalties may be effective in escaping from the underdevelopment trap, but too much controls and penalties in an underdeveloped area may have perverse effects. 
Corollary: The relevant configurations of parameters can be of three types, and for each type a different mix of effects due to changes in $z$ and $m$ emerges as follows:

$$
\begin{aligned}
& \text { if } \frac{1+m}{1+t}<\frac{\eta-\alpha}{1-\alpha}\left(<\frac{\eta-\alpha}{\alpha(1-\alpha)}\right) \text {, then } \frac{\partial E^{*}}{\partial z}>0 \text { and } \frac{\partial E^{*}}{\partial m}>0 \\
& \text { if } \frac{\eta-\alpha}{1-\alpha}<\frac{1+m}{1+t}<\frac{\eta-\alpha}{\alpha(1-\alpha)} \text {, then } \frac{\partial E^{*}}{\partial z}>0 \text { and } \frac{\partial E^{*}}{\partial m}<0 \\
& \text { if }\left(\frac{\eta-\alpha}{1-\alpha}<\right) \frac{\eta-\alpha}{\alpha(1-\alpha)}<\frac{1+m}{1+t} \text {, then } \frac{\partial E^{*}}{\partial z}<0 \text { and } \frac{\partial E^{*}}{\partial m}<0 .
\end{aligned}
$$

Whereas $\frac{\partial E^{*}}{\partial \eta}$ is generally positive.

Proof: It follows from Propositions 3, 4 and 5.

This schema suggests that individual entrepreneurial ability is a key factor, because if a policy is able to increase it, the effects are always positive, and if it is lacking, it may hinder the other policies.

\section{Conclusions}

The theoretical literature on the underground economy is meagre, and it concentrates mainly on the microeconomic aspects of tax evasion. The phenomenon of the underground economy is instead recognised as important by empirical studies, which also reveal that it is not evenly distributed, but is more widespread in less developed areas. This fact has prompted the present paper, which attempts to explain the different coexistence of the underground economy with the official economy in a more developed area with respect to a less developed one. 
Unfortunately, underground economic behaviour is very heterogeneous, and difficult to observe, so that it cannot be easily stylised. Nevertheless, a few plausible hypotheses can be put forward regarding some important features of this phenomenon. Firstly, firms hire unregistered labour only partly, side by side with official employees. Secondly, firms use the two different kinds of labour more as complements to each other than as substitutes. This is because official labour implies a more stable relationship with the entrepreneur, so that greater efficiency may ensue. Thirdly, entrepreneurship is important in explanation of the abandonment by a firm of small-sized and low-productive processes largely based on unregistered labour. Fourthly, entrepreneurship depends, in a given area, on individual ability, which may be very heterogeneous, and across different areas, on the density of enterprises, which is likely to give rise to positive externalities. In particular, the literature on industrial districts emphasises the importance of a critical density which generates an acceleration in economic development.

On the basis of these hypotheses the model proposed is able to substantiate the following results: ${ }^{13}$

- an equilibrium both micro- and macro-economic exists when firms find it convenient to employ both unregistered and official labour;

- the degree of regularisation by each firm depends on entrepreneurship and on the relative fiscal burden; in particular, the better the entrepreneur's ability, the greater the demand for official labour, thus implying a more efficient and large firm;

${ }^{13}$ A refinement of the model could give better specification to the behaviour of the workers, who are here assumed to be homogeneous, and with a very simplistic (and implicit) utility function. 
- in the macro-economic equilibrium the number of firms, their size, the overall productivity and output are determined as well;

- if a critical density of enterprises exists, two stable equilibria can be determined: a "good" equilibrium where the economy is populated by many firms, with high productivity and output and low degree of labour regularisation; and a "bad" equilibrium with the reverse features, which can thus be termed an underdevelopment trap;

- the possibility of escaping from the underdevelopment trap, or at any rate of increasing the level of regularisation and overall efficiency, derives from policy measures designed to improve entrepreneurship, especially when the improvement is evenly distributed;

- by contrast, tighter fiscal controls have overall perverse effects if entrepreneurship is particularly scarce.

These results are of particularly relevance to the debate on the underground economy in the Southern areas of Italy. In fact, these results suggest that an economy may fall into an undervelopment trap when underground activities are particularly convenient, although not exhaustive but rather complementary. The best policies suggested are those intended to improve entrepreneurship, especially through educational policies. The policies directly targeted on combatting the underground economy, like tighter controls and penalties, appear to be effective only when entrepreneurship is sufficiently developed and evenly distributed across firms.

Therefore, in order to reduce the underground economy, the most effective policy is to make registered labour more convenient, rather than to make 
unregistered labour less convenient. The best strategy appears to be that of combatting underdevelopment, rather than underground activities as such. ${ }^{14}$

\section{Appendix 1}

The expression on the LHS of the equation (14) is decreasing for $E \rightarrow+\infty$, and it tends to $+\infty$ for $E \rightarrow 0$; while the expression on the RHS is always increasing and is equal to 0 for $E=0$. This implies that the two curves intersect each other at least once.

Moreover, given that the zero-profit curve (eq.(10)) may change its course twice, as in Fig. 4, the curves may intersect with each other three times: twice in the descending traits of the zero-profit curve, and once in the increasing trait.

${ }^{14}$ A very recent paper on the effects of the underground economy on unemployment reaches an analogous conclusion. By adopting a very different model Boeri and Garibaldi (2000) conclude that the best policy for reducing unemployment is to raise overall productivity or to combat it directly, rather than to increase penalties on the underground activities, which may have perverse effects. 


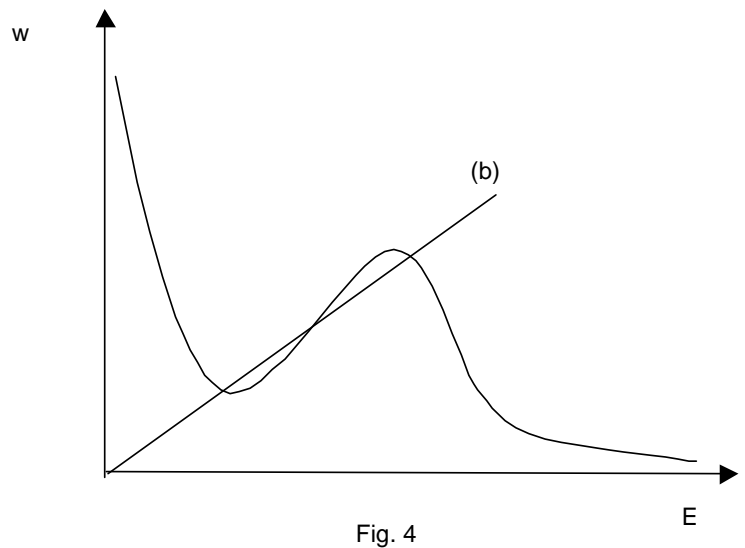

Stability requires $\frac{\partial w_{P}}{\partial E}<\frac{\partial w_{L}}{\partial E}$ calculated over equilibrium values of $E$.

This condition holds only when the two curves intersect in the decreasing traits of the zero-profits curve where $\frac{\partial w_{P}}{\partial E}<0$ (see fig. 4).

\section{Appendix 2}

i) Aggregate output is:

$$
Y=\int_{0}^{E^{*}} y_{i} d i=\int_{0}^{E^{*}}\left[\left(\frac{1}{w^{*}}\right)^{\frac{\alpha}{1-\alpha}}\left[\left(\frac{\alpha}{1+t}\right)^{\frac{\alpha}{1-\alpha}}\left(\frac{\eta E_{i}^{\eta-1}}{1+e^{v-z E}}\right)+\beta\left(\frac{\alpha \beta}{1+m}\right)^{\frac{\alpha}{1-\alpha}}\right]\right] d i
$$

Solving the integral and substituting equation (13) we have:

$$
Y=\frac{\left(\frac{\alpha}{1+t}\right)^{\frac{\alpha}{1-\alpha}}\left(\frac{\eta E^{* \eta-\alpha}}{1+e^{\nu-z E^{*}}}\right)^{\frac{1}{1-\alpha}} \frac{1-\alpha}{\eta-\alpha}+\beta^{\frac{1}{1-\alpha}}\left(\frac{\alpha}{1+m}\right)^{\frac{\alpha}{1-\alpha}} E^{*}}{\left(\left(\frac{\alpha}{1+t}\right)^{\frac{1}{1-\alpha}}\left(\frac{\eta E^{* \eta-\alpha}}{1+e^{\nu-z E^{*}}}\right)^{\frac{1}{1-\alpha}} \frac{1-\alpha}{\eta-\alpha}+\left(\frac{\beta \alpha}{1+m}\right)^{\frac{1}{1-\alpha}} E^{*}\right)^{\alpha}}
$$


The derivative of this expression with respect to $E^{*}$ is always positive if $\frac{1+m}{1+t}>\alpha$. In this case a larger number of firms will give rise to a greater amount of aggregate output.

ii) The aggregate output can be rewritten as: $Y=\frac{\left(\frac{\alpha}{1+t}\right)^{\frac{\alpha}{1-\alpha}} B\left(E^{*}\right)^{\frac{1}{1-\alpha}} E^{*} \frac{1-\alpha}{\eta-\alpha}+\beta^{\frac{1}{1-\alpha}}\left(\frac{\alpha}{1+m}\right)^{\frac{\alpha}{1-\alpha}} E^{*}}{\left(\left(\frac{\alpha}{1+t}\right)^{\frac{1}{1-\alpha}} B\left(E^{*}\right)^{\frac{1}{1-\alpha}} E^{*} \frac{1-\alpha}{\eta-\alpha}+\left(\frac{\beta \alpha}{1+m}\right)^{\frac{1}{1-\alpha}} E^{*}\right)^{\alpha}}$ whose derivative with respect to $B(E)$ is positive (where $B(E)=\frac{\eta E^{\eta-1}}{1+e^{v-2 E}}$ ). While the ratio between official and unregistered labour is given by $g_{i}=\left\{\frac{B\left(E_{i}\right)(1+m)}{\beta(1+t)}\right\}^{\frac{1}{1-\alpha}}$, which is positively related to $B(E)$. Hence, if high equilibrium has a higher $B(E)$, it will have also a higher $\mathrm{g}_{\mathrm{i}}$.and a higher aggregate output.

If we rewrite equilibrium condition (eq. 14) as follows:

$\frac{(1-\alpha)}{\bar{c}} B(E)^{\frac{1}{1-\alpha}}\left(\frac{\alpha}{1+t}\right)^{\frac{\alpha}{1-\alpha}}=\left(\left(\frac{\alpha}{1+t}\right)^{\frac{1}{1-\alpha}}\left(\frac{\eta E^{\eta-\alpha}}{1+e^{v-z E}}\right)^{\frac{1}{1-\alpha}} \frac{1-\alpha}{\eta-\alpha}+E\left(\frac{\beta \alpha}{1+m}\right)^{\frac{1}{1-\alpha}}\right)^{\alpha}-\beta\left(\frac{\beta \alpha}{1+m}\right)^{\frac{\alpha}{1-\alpha}}$

it is easily recoverable that the expression on the RHS is increasing in $E^{*}$. Then by increasing $E^{*}$, the expression on the LHS, which is positively related to $B\left(E^{*}\right)$, must increase. But, if the parameter values do not change, this implies an increase in $B\left(E^{*}\right)$. In the case of multiple equilibria, the parameters assume equal values, therefore the equilibrium characterised by a greater number of firms must have also a higher $B\left(E^{*}\right)$, and thus a higher aggregate output, as well as a higher $g_{i}$. 


\section{Appendix 3}

Rewriting equation (14) as:

$$
\begin{aligned}
& F=\left(\frac{1-\alpha}{\bar{c}}\right)^{\frac{1}{\alpha}}\left[\left(\frac{\eta E^{\eta-1}}{1+e^{\nu-z E}}\right)^{\frac{1}{1-\alpha}}\left(\frac{\alpha}{1+t}\right)^{\frac{\alpha}{1-\alpha}}+\beta\left(\frac{\beta \alpha}{1+m}\right)^{\frac{\alpha}{1-\alpha}}\right]^{\frac{1}{\alpha}} \\
& -\left(\frac{\alpha}{1+t}\right)^{\frac{1}{1-\alpha}}\left(\frac{\eta E^{\eta-\alpha}}{1+e^{\nu-z E}}\right)^{\frac{1}{1-\alpha}} \frac{1-\alpha}{\eta-\alpha}-E\left(\frac{\beta \alpha}{1+m}\right)^{\frac{1}{1-\alpha}}=0
\end{aligned}
$$

Stable equilibria require that $F_{E}<0$. Hence, for the implicit function theorem, $\operatorname{sign} \frac{\partial E^{*}}{\partial x}=\operatorname{sign} F_{x}$, for $x=z, m, \eta$. In particular, we have:

(A4.1) $\frac{\partial E^{*}}{\partial \eta}>0 \Rightarrow\left(\frac{1-\alpha}{\bar{c}}\right)^{\frac{1}{\alpha}}\left[\left(\frac{\eta E^{\eta-1}}{1+e^{\nu-z E}}\right)^{\frac{1}{1-\alpha}}\left(\frac{\alpha}{1+t}\right)^{\frac{\alpha}{1-\alpha}}+\beta\left(\frac{\beta \alpha}{1+m}\right)^{\frac{\alpha}{1-\alpha}}\right]^{\frac{1-\alpha}{\alpha}}>\left[E \frac{\alpha^{2}}{1+t}\right]$ (A4.2) $\frac{\partial E^{*}}{\partial z}>0 \Rightarrow\left(\frac{1-\alpha}{c}\right)^{\frac{1}{\alpha}}\left[\left(\frac{\eta E^{\eta-1}}{1+e^{v-z E}}\right)^{\frac{1}{1-\alpha}}\left(\frac{\alpha}{1+t}\right)^{\frac{\alpha}{1-\alpha}}+\beta\left(\frac{\beta \alpha}{1+m}\right)^{\frac{\alpha}{1-\alpha}}\right]^{\frac{1-\alpha}{\alpha}}>\left[E \frac{\alpha^{2}}{1+t} \frac{1-\alpha}{\eta-\alpha}\right]$ (A4.3) $\frac{\partial E^{*}}{\partial m}>0 \Rightarrow\left(\frac{1-\alpha}{c}\right)^{\frac{1}{\alpha}}\left[\left(\frac{\eta E^{\eta-1}}{1+e^{\nu-z E}}\right)^{\frac{1}{1-\alpha}}\left(\frac{\alpha}{1+t}\right)^{\frac{\alpha}{1-\alpha}}+\beta\left(\frac{\beta \alpha}{1+m}\right)^{\frac{\alpha}{1-\alpha}}\right]^{\frac{1-\alpha}{\alpha}}<\left[E \frac{\alpha}{1+m}\right]^{\frac{1}{1-\alpha}}$.

In order to show that inequality (A4.1) is always true, while inequality s (A4.23 ) are conditioned, let us again rewrite the equilibrium condition (eq. 14) as: 


$$
\begin{aligned}
& A \equiv\left(\frac{1-\alpha}{\bar{c}}\right)^{\frac{1}{\alpha}}\left[\left(\frac{\eta E^{\eta-1}}{1+e^{\nu-z E}}\right)^{\frac{1}{1-\alpha}}\left(\frac{\alpha}{1+t}\right)^{\frac{\alpha}{1-\alpha}}+\beta\left(\frac{\beta \alpha}{1+m}\right)^{\frac{\alpha}{1-\alpha}}\right]^{\frac{1}{\alpha}} \\
& =\left(\frac{\alpha}{1+t}\right)^{\frac{1}{1-\alpha}}\left(\frac{\eta E^{\eta-\alpha}}{1+e^{\nu-z E}}\right)^{\frac{1}{1-\alpha}} \frac{1-\alpha}{\eta-\alpha}+E\left(\frac{\beta \alpha}{1+m}\right)^{\frac{1}{1-\alpha}} \equiv B
\end{aligned}
$$

Then let us rewrite inequality (A4.1) thus:

$$
\begin{aligned}
& A \equiv\left(\frac{1-\alpha}{c}\right)^{\frac{1}{\alpha}}\left[\left(\frac{\eta E^{\eta-1}}{1+e^{v-z E}}\right)^{\frac{1}{1-\alpha}}\left(\frac{\alpha}{1+t}\right)^{\frac{\alpha}{1-\alpha}}+\beta\left(\frac{\beta \alpha}{1+m}\right)^{\frac{\alpha}{1-\alpha}}\right]^{\frac{1}{\alpha}} \\
& >\alpha\left(\frac{\eta E^{\eta-\alpha}}{1+e^{v-z E}}\right)^{\frac{1}{1-\alpha}}\left(\frac{\alpha}{1+t}\right)^{\frac{1}{1-\alpha}}+\beta\left(\frac{\beta \alpha}{1+m}\right)^{\frac{\alpha}{1-\alpha}} E \frac{\alpha^{2}}{1+t} \equiv u
\end{aligned}
$$

Since, $B>u$ because:

$$
\left(\frac{\alpha}{1+t}\right)^{\frac{1}{1-\alpha}}\left(\frac{\eta E^{\eta-\alpha}}{1+e^{\nu-z E}}\right)^{\frac{1}{1-\alpha}}\left(\frac{1-\alpha}{\eta-\alpha}-\alpha\right)+E\left(\frac{\beta \alpha}{1+m}\right)^{\frac{1}{1-\alpha}}\left(1-\frac{1+m}{1+t}\right)>0 .
$$

This implies that $\frac{\partial E^{*}}{\partial \eta}$ is always positive. From this proposition 3 follows.

Let us rewrite inequality (A4.2) thus:

$$
A>(<)\left[\frac{\alpha(1-\alpha)}{\eta-\alpha}\right]\left(\frac{\eta E^{\eta-\alpha}}{1+e^{\nu-z E}}\right)^{\frac{1}{1-\alpha}}\left(\frac{\alpha}{1+t}\right)^{\frac{1}{1-\alpha}}+\beta\left(\frac{\beta \alpha}{1+m}\right)^{\frac{\alpha}{1-\alpha}}\left[E \frac{\alpha(1-\alpha)}{\eta-\alpha} \frac{\alpha}{1+t}\right] \equiv x
$$

Since:

$$
\begin{aligned}
& B-x=\left(\frac{\alpha}{1+t}\right)^{\frac{1}{1-\alpha}} \frac{(1-\alpha)^{2}}{\eta-\alpha}\left(\frac{\eta E^{\eta-1}}{1+e^{v-z E}}\right)^{\frac{1}{1-\alpha}}+(\beta \alpha)^{\frac{1}{1-\alpha}}\left(\frac{1}{1+m}\right)^{\frac{\alpha}{1-\alpha}}\left[\frac{\eta-\alpha}{\alpha(1-\alpha)}-\frac{1+m}{1+t}\right]>0 \\
& \text { if } \frac{1+m}{1+t}<\frac{\eta-\alpha}{\alpha(1-\alpha)}
\end{aligned}
$$


This implies that $\frac{\partial E^{*}}{\partial z}$ is positive; however, if $\frac{1+m}{1+t}>\frac{\eta-\alpha}{\alpha(1-\alpha)}$, the sign of $\frac{\partial E^{*}}{\partial z}$ is ambiguous, but when $E \rightarrow 0$ the positive term is greater. Instead, for $E \rightarrow+\infty$, the negative term prevails. From these proposition 4 follows.

Let us rewrite inequality (A4.3) thus:

$$
A<(>)\left[\frac{\alpha}{1+m}\right]\left(\frac{\eta E^{\eta-\alpha}}{1+e^{\nu-z E}}\right)^{\frac{1}{1-\alpha}}\left(\frac{\alpha}{1+t}\right)^{\frac{\alpha}{1-\alpha}}+E\left(\frac{\beta \alpha}{1+m}\right)^{\frac{1}{1-\alpha}} \equiv y
$$

Since:

$B-y=\left(\frac{\eta E^{\eta-\alpha}}{1+e^{v-z E}}\right)^{\frac{1}{1-\alpha}}\left(\frac{\alpha}{1-\alpha}\right)^{\frac{1}{1-\alpha}}\left(\frac{1-\alpha}{\eta-\alpha}-\frac{1+t}{1+m}\right)<(>) 0 \quad$ if $\quad \frac{1+m}{1+t}<(>) \frac{\eta-\alpha}{1-\alpha}, \quad \frac{\partial E^{*}}{\partial m}$ is positive if this condition holds. 


\section{References}

Acemoglu, D. (1997) Training and Innovation in an Imperfect Labour Market, Review of Economic Studies, 64, 445-464.

Agenor P.R. e J. Aizenman (1999) Macroeconomic adjustment with segmented labour markets, Journal of Development Economics, 58, 277-96

Aghion, P. and P. Howitt, (1998) Endogenous Growth Theory, MIT Press, Cambridge, Massachusetts

Baumol, W. J. (1990). Entrepreneurship: Productive, Unproductive, and Destructive. Journal of Political Economy, 98(5)-I, 893-921.

Becattini, G. (1979) Dal "settore" industriale al "distretto" industriale, Rivista di Economia e Politica Industriale, no.1, Jan.-Apr.

Bennett, J. (1990) Keynesian unemployment and the shadow economy, Journal of Macroeconomics, 12(2), 289-305

Bental B., U. Ben-Zion and A. Wenig (1985) Macroeconomic Policy and the Shadow Economy, in W. Gaertner and A. Wenig (eds) The Economics of Shadow Economy, Springer, Berlin, pp.179-193

Boeri, T. and P. Garibaldi (2000) Shadow Activity and Unemployment in a Depressed Labour Market, Bocconi University (mimeo)

Bonatti, L. (2000) Limpatto del sistema pensionistico sulle dimensioni dell'economia informale, Rivista di Economia Politica, 90(1), 57-73

Brunetta, R. and A. Ceci (1998) Underground Employment in Italy: Its Causes, Its Extent and the Costs and Benefits of Regularization, Review of Economic Conditions in Italy; 0(2), May-Aug., 257-89.

Burdett, K. and E. Smith (1996) Education and Matching Externalities, in Booth, A. and D. Snower (1996), Skill Gap and Economic Activity, Cambridge: Cambridge University Press 
Commissione Lavoro della Camera dei Deputati (1998) Lavoro nero e minorile, Roma

Donolo, C. and M. Capparucci (1999) (eds) Per una strategia dell'emersione: analisi del fenomeno-sommerso attraverso lo studio di casi paradigmatici di "hon regolarità" per l'individuazione e la valutazione di policies, mimeo, Roma

De Gijsel, P. (1985) A Microeconomic Analysis of Black Labour Demand and Supply, in W. Gaertner and A. Wenig (eds) The Economics of Shadow Economy, Springer, Berlin, pp.218-26

European Commission (1998) Paper on undeclared works, DG V, Bruxelles

Feige, E. L. (1989) (ed.) The Underground Economies, Cambridge University Press, Cambridge

Ginsburgh, V., P. Michel and F. Padoa-Schioppa (1985) Macroeconomic policy in the presence of an irregular sector, in W. Gaertner and A. Wenig (eds) The Economics of Shadow Economy, Springer, Berlin, pp.218-26

Johnson, S., Kaufmann, D. and P. Zoido-Lobaton (1998) Regulatory Discretion and the Unofficial Economy, American Economic Review, 88(2), May, $387-92$.

Lippert, O. and M. Walker (1997) The Underground Economy: Global Evidence of its Size and Impact, Vancouver:Fraser Institute

Loayza, N.V. (1996) The Economics of Informal Sector: a Simple Model and Some Empirical Evidence from Latin America, Carnegie Rochester Conference Series Public Policy 45, 129-162

Lucas, R.E. (1978). On the Size Distribution of Business Firms. Bell Journal of Economics. 9, 508-523.

Murphy, K. M., A. Shleifer and R. W. Vishny (1991) The Allocation of Talent: Implications for Growth, Quarterly Journal of Economics, 106, May, 50330 
OECD (1997) Taxation and Economic Performance, by W. Leibfritz, J. Thornton and A. Bibbie, Economic Department Working Papers, no.176

Paci, R. (1997) More Similar and Less Equal, Economic Growth in the European Regions, Weltwirtshaftliches Archiv, 133(4), 609-34

Petersen, S. (1998) The Shadow Economy in Western Europe. Measurement and Results for Selected Countries, The Rockwool Foundation Research Unit, Copenhagen

Pugno, M. (2000) Economia sommersa e disoccupazione: un modello per l' analisi e le politiche di intervento, Rivista Italiana degli Economisti, no.2, 269-290

Rauch, J. (1991) Modelling the Informal Sector Formally, Journal of Development Economics, 35, 33-47

Schneider, F. and D. Enste (2000) Shadow Economies: Size, Causes, and Consequences, Journal of Economic Literature, 38, 77-114

Schneider, F. (1997) Empirical Results of the Size of the Shadow Economy of 17 Oecd Countries over Time, Department of Economics, University of Linz, Austria

Stevens, M. (1994) An Investment Model for the Supply of Training by Employers, Economic Journal, 104, 556-570

Tanzi, V. (1980) Underground Economy and Tax evasion in the US: Estimates and Implications, Banca Nazionale del Lavoro Quarterly Review, 32, 427-55

Tanzi, V. (1999) Uses and Abuses of Estimates of the Underground Economy, Economic Journal, 109, June, F338-47

Tondl, G. (1999) The Changing Pattern of Regional Convergence in Europe, Jahrbuch fuer Regionalwissenschaft/Review of Regional Research; 19(1), $1-33$ 
Elenco dei papers del Dipartimento di Economia

1989. 1. Knowledge and Prediction of Economic Behaviour: Towards A Constructivist Approach. by Roberto Tamborini.

1989. 2. Export Stabilization and Optimal Currency Baskets: the Case of Latin AmericanCountries. by Renzo G.Avesani Giampiero M. Gallo and Peter Pauly.

1989. 3. Quali garanzie per i sottoscrittori di titoli di Stato? Una rilettura del rapporto della Commissione Economica dell'Assemblea Costituente di Franco Spinelli e Danilo Vismara.

(What Guarantees to the Treasury Bill Holders? The Report of the Assemblea Costituente Economic Commission Reconsidered by Franco Spinelli and Danilo Vismara.)

1989. 4. L'intervento pubblico nell'economia della "Venezia Tridentina" durante l'immediato dopoguerra di Angelo Moioli.

(The Public Intervention in "Venezia Tridentina" Economy in the First War Aftermath by Angelo Moioli.)

1989. 5. L'economia lombarda verso la maturità dell'equilibrio agricolo-commerciale durante l'età delle riforme di Angelo Moioli.

(The Lombard Economy Towards the Agriculture-Trade Equilibrium in the Reform Age by Angelo Moioli.)

1989. 6. L'identificazione delle allocazioni dei fattori produttivi con il duale. di Quirino Paris e di Luciano Pilati.

(Identification of Factor Allocations Through the Dual Approach by Quirino Paris and Luciano Pilati.)

1990. 1. Le scelte organizzative e localizzative dell'amministrazione postale: un modello intrpretativo.di Gianfranco Cerea.

(The Post Service's Organizational and Locational Choices: An Interpretative Model by Gianfranco Cerea.)

1990. 2. Towards a Consistent Characterization of the Financial Economy. by Roberto Tamborini.

1990. 3. Nuova macroeconomia classica ed equilibrio economico generale: considerazioni sulla pretesa matrice walrasiana della N.M.C. di Giuseppe Chirichiello. 
(New Classical Macroeconomics and General Equilibrium: Some Notes on the Alleged Walrasian Matrix of the N.C.M.by Giuseppe Chirichiello.)

1990. 4. Exchange Rate Changes and Price Determination in Polypolistic Markets. by Roberto Tamborini.

1990. 5. Congestione urbana e politiche del traffico. Un' analisi economica di Giuseppe Folloni e Gianluigi Gorla.

(Urban Congestion and Traffic Policy. An Economic Analysis by Giuseppe Folloni and Gianluigi Gorla.)

1990. 6. Il ruolo della qualità nella domanda di servizi pubblici. Un metodo di analisi empirica di Luigi Mittone.

(The Role of Quality in the Demand for Public Services. A Methodology for Empirical Analysis by Luigi Mittone.)

1991. 1. Consumer Behaviour under Conditions of Incomplete Information on Quality: a Note by Pilati Luciano and Giuseppe Ricci.

1991. 2. Current Account and Budget Deficit in an Interdependent World by Luigi Bosco.

1991. 3. Scelte di consumo, qualità incerta e razionalità limitata di Luigi Mittone e Roberto Tamborini.

(Consumer Choice, Unknown Quality and Bounded Rationality by Luigi Mittone and Roberto Tamborini.)

1991. 4. Jumping in the Band: Undeclared Intervention Thresholds in a Target Zone by Renzo G. Avesani and Giampiero M. Gallo.

1991. 5 The World Tranfer Problem. Capital Flows and the Adjustment of Payments by Roberto Tamborini.

1992.1 Can People Learn Rational Expectations? An Ecological Approach by Pier Luigi Sacco.

1992.2 On Cash Dividends as a Social Institution by Luca Beltrametti.

1992.3 Politica tariffaria e politica informativa nell' offerta di servizi pubblici di Luigi Mittone 
(Pricing and Information Policy in the Supply of Public Services by Luigi Mittone.)

1992.4 Technological Change, Technological Systems, Factors of Production by Gilberto Antonelli and Giovanni Pegoretti.

1992.5 Note in tema di progresso tecnico di Geremia Gios e Claudio Miglierina.

(Notes on Technical Progress, by Geremia Gios and Claudio Miglierina).

1992.6 Deflation in Input Output Tables by Giuseppe Folloni and Claudio Miglierina.

1992.7 Riduzione della complessità decisionale: politiche normative e produzione di informazione di Luigi Mittone

(Reduction in decision complexity: normative policies and information production by Luigi Mittone)

1992.8 Single Market Emu and Widening. Responses to Three Institutional Shocks in the European Community by Pier Carlo Padoan and Marcello Pericoli

1993.1 La tutela dei soggetti "privi di mezzi": Criteri e procedure per la valutazione della condizione economica di Gianfranco Cerea

(Public policies for the poor: criteria and procedures for a novel means test by Gianfranco Cerea )

1993.2 La tutela dei soggetti "privi di mezzi": un modello matematico per la rappresentazione della condizione economica di Wolfgang J. Irler

(Public policies for the poor: a mathematical model for a novel means test by Wolfgang J.Irler)

1993.3 Quasi-markets and Uncertainty: the Case of General Proctice Service by Luigi Mittone

1993.4 Aggregation of Individual Demand Functions and Convergence to Walrasian Equilibria by Dario Paternoster

1993.5 A Learning Experiment with Classifier System: the Determinants of the Dollar-Mark Exchange Rate by Luca Beltrametti, Luigi Marengo and Roberto Tamborini 
1993.6 Alcune considerazioni sui paesi a sviluppo recente di Silvio Goglio

(Latecomer Countries: Evidence and Comments by Silvio Goglio)

1993.7 Italia ed Europa: note sulla crisi dello SME di

Luigi Bosco

(Italy and Europe: Notes on the Crisis of the EMS by Luigi Bosco)

1993.8 Un contributo all' analisi del mutamento strutturale nei modelli input-output di Gabriella Berloffa

(Measuring Structural Change in Input-Output Models: a Contribution by Gabriella Berloffa)

1993.9 On Competing Theories of Economic Growth: a Cross-country Evidence by Maurizio Pugno

1993.10 Le obbligazioni comunali di Carlo Buratti (Municipal Bonds by Carlo Buratti)

1993.11 Due saggi sull' organizzazione e il finanziamento della scuola statale di Carlo Buratti

(Two Essays on the Organization and Financing of Italian State Schools by Carlo Buratti

1994.1 Un' interpretazione della crescita regionale:leaders, attività indotte e conseguenze di policy di Giuseppe Folloni e Silvio Giove. (A Hypothesis about regional Growth: Leaders, induced Activities and Policy by Giuseppe Folloni and Silvio Giove).

1994.2 Tax evasion and moral constraints: some experimental evidence by Luigi Bosco and Luigi Mittone.

1995.1 A Kaldorian Model of Economic Growth with Shortage of Labour and Innovations by Maurizio Pugno.

1995.2 A che punto è la storia d'impresa? Una riflessione storiografica e due ricerche sul campo a cura di Luigi Trezzi.

1995.3 Il futuro dell' impresa cooperativa: tra sistemi, reti ed ibridazioni di Luciano Pilati.

(The future of the cooperative enterprise: among systems, networks and hybridisation by Luciano Pilati). 
1995.4 Sulla possibile indeterminatezza di un sistema pensionistico in perfetto equilibrio finanziario di Luca Beltrametti e Luigi Bonatti. (On the indeterminacy of a perfectly balanced social security system by Luca Beltrametti and Luigi Bonatti).

1995.5 Two Goodwinian Models of Economic Growth for East Asian NICs by Maurizio Pugno.

1995.6 Increasing Returns and Externalities: Introducing Spatial Diffusion into Krugman's Economic Geography by Giuseppe Folloni and Gianluigi Gorla.

1995.7 Benefit of Economic Policy Cooperation in a Model with Current Account Dynamics and Budget Deficit by Luigi Bosco.

1995.8 Coalition and Cooperation in Interdependent Economies by Luigi Bosco.

1995.9 La finanza pubblica italiana e l' ingresso nell' unione monetaria europea di Ferdinando Targetti.

(Italian Public Finance and the Entry in the EMU by Ferdinando Targetti)

1996.1 Employment, Growth and Income Inequality: some open Questions by Annamaria Simonazzi and Paola Villa.

1996.2 Keynes' Ideaof Uncertainty: a Proposal for its Quantification by Guido Fioretti.

1996.3 The Persistence of a "Low-Skill, Bad-Job Trap" in a Dynamic Model of a Dual Labor Market by Luigi Bonatti.

1996.4 Lebanon: from Development to Civil War by Silvio Goglio.

1996.5 A Mediterranean Perspective on the Break-Down of the Relationship between Participation and Fertility by Francesca Bettio and Paola Villa.

1996.6 Is there any persistence in innovative activities? by Elena Cefis.

1997.1 Imprenditorialità nelle alpi fra età moderna e contemporanea a cura di Luigi Trezzi. 
1997.2 Il costo del denaro è uno strumento anti-inflazionistico? di Roberto Tamborini.

(Is the Interest Rate an Anti-Inflationary Tool? by Roberto Tamborini).

1997.3 A Stability Pact for the EMU? by Roberto Tamborini.

1997.4 Mr Keynes and the Moderns by Axel Leijonhufvud.

1997.5 The Wicksellian Heritage by Axel Leijonhufvud.

1997.6 On pension policies in open economies by Luca Beltrametti and Luigi Bonatti.

1997.7 The Multi-Stakeholders Versus the Nonprofit Organisation by Carlo Borzaga and Luigi Mittone.

1997.8 How can the Choice of a Tme-Consistent Monetary Policy have Systematic Real Effects? by Luigi Bonatti.

1997.9 Negative Externalities as the Cause of Growth in a Neoclassical Model by Stefano Bartolini and Luigi Bonatti.

1997.10 Externalities and Growth in an Evolutionary Game by Angelo Antoci and Stefano Bartolini.

1997.11 An Investigation into the New Keynesian Macroeconomics of Imperfect Capital Markets by Roberto Tamborini.

1998.1 Assessing Accuracy in Transition Probability Matrices by Elena Cefis and Giuseppe Espa.

1998.2 Microfoundations: Adaptative or Optimizing? by Axel Leijonhufvud.

1998.3 Clower's intellectual voyage: the 'Ariadne's thread' of continuity through changes by Elisabetta De Antoni.

1998.4 The Persistence of Innovative Activities. A Cross-Countries and Cross-Sectors Comparative Analysis by Elena Cefis and Luigi Orsenigo 
1998.5 Growth as a Coordination Failure by Stefano Bartolini and Luigi Bonatti

1998.6 Monetary Theory and Central Banking by Axel Leijonhufvud

1998.7 Monetary policy, credit and aggregate supply: the evidence from Italy by Riccardo Fiorentini and Roberto Tamborini

1998.8 Stability and multiple equilibria in a model of talent, rent seeking, and growth by Maurizio Pugno

1998.9 Two types of crisis by Axel Leijonhufvud

1998.10 Trade and labour markets: vertical and regional differentiation in Italy by Giuseppe Celi e Maria Luigia Segnana

1998.11 Utilizzo della rete neurale nella costruzione di un trading system by Giulio Pettenuzzo

1998.12 The impact of social security tax on the size of the informal economy by Luigi Bonatti

1999.1 L'economia della montagna interna italiana: un approccio storiografico, a cura di Andrea Leonardi e Andrea Bonoldi.

1999.2 Unemployment risk, labour force participation and savings, by Gabriella Berloffa e Peter Simmons

1999.3 Economia sommersa, disoccupazione e crescita, by Maurizio Pugno

1999.4 The nationalisation of the British Railways in Uruguay, by Giorgio Fodor

1999.5 Elements for the history of the standard commodity, by Giorgio Fodor

1999.6 Financial Market Imperfections, Heterogeneity and growth, by Edoardo Gaffeo

1999.7 Growth, real interest, employment and wage determination, by Luigi Bonatti 
2000.1 A two-sector model of the effects of wage compression on unemployment and industry distribution of employment, by Luigi Bonatti

2000.2 From Kuwait to Kosovo: What have we learned? Reflections on globalization and peace, by Roberto Tamborini

2000.3 Metodo e valutazione in economia. Dall'apriorismo a Friedman, by Matteo Motterlini

2000.4 Under tertiarisation and unemployment. by Maurizio Pugno

2001.1 Growth and Monetary Rules in a Model with Competitive Labor Markets, by Luigi Bonatti.

2001.2 Profit Versus Non-Profit Firms in the Service Sector: an Analysis of the Employment and Welfare Implications, by Luigi Bonatti, Carlo Borzaga and Luigi Mittone.

2001.3 Statistical Economic Approach to Mixed Stock-Flows Dynamic Models in Macroeconomics, by Bernardo Maggi and Giuseppe Espa.

2001.4 The monetary transmission mechanism in Italy: The credit channel and a missing ring, by Riccardo Fiorentini and Roberto Tamborini.

2001.5 Vat evasion: an experimental approach, by Luigi Mittone

2001.6 Decomposability and Modularity of Economic Interactions, by Luigi Marengo, Corrado Pasquali and Marco Valente.

2001.7 Unbalanced Growth and Women's Homework, by Maurizio Pugno

2002.1 The Underground Economy and the Underdevelopment Trap, by Maria Rosarua Carillo and Maurizio Pugno 
PUBBLICAZIONE REGISTRATA PRESSO IL TRIBUNALE DI TRENTO 
